\title{
Review Article \\ Soybean Curd Residue: Composition, Utilization, and Related Limiting Factors
}

\author{
Shuhong Li, Dan Zhu, Kejuan Li, Yingnan Yang, Zhongfang Lei, and Zhenya Zhang \\ Graduate School of Life and Environmental Sciences, University of Tsukuba, 1-1-1 Tennodai, Tsukuba, Ibaraki 305-8572, Japan \\ Correspondence should be addressed to Zhenya Zhang; zhang.zhenya.fu@u.tsukuba.ac.jp
}

Received 24 May 2013; Accepted 2 July 2013

Academic Editors: M. D. Bermejo and J. Rajabathar

Copyright (C) 2013 Shuhong Li et al. This is an open access article distributed under the Creative Commons Attribution License, which permits unrestricted use, distribution, and reproduction in any medium, provided the original work is properly cited.

\begin{abstract}
The production of soybean products has been increasing throughout the world, and there has been a corresponding increase in the quantity of soybean curd residue (SCR) being thrown out. The dumping of SCR has become a problem to be solved due to its contamination to the environment. SCR is rich in fiber, fat, protein, vitamins, and trace elements. It has potential for valueadded processing and utilization; options that simultaneously hold the promise of increased economic benefit as well as decreased pollution potential for the environment. The objective of this study is to fully investigate, review, and summarize the existing literature in order to develop a comprehensive knowledge base for the composition and reuse of SCR. It is evident from the literature survey that SCR shows good potential as a functional food material. However, there are several drawbacks to the use of SCR and corresponding solutions presented in this paper.
\end{abstract}

\section{Introduction}

Soy milk and tofu have maintained wide popularity as food sources for thousands of years, and large quantities of their byproducts are generated during the manufacturing process [1]. In Asian countries, soybean is made into various foods such as tofu, soymilk, soymilk powder, bean sprouts, dried tofu, soy sauce, soy flour, and tempeh soybean oil. Soybean curd residue (SCR), namely, okara in Japanese, is the main surplus material of soybean products, and it is often regarded as waste. About $1.1 \mathrm{~kg}$ of fresh SCR is produced from every kilogram of soybeans processed into soymilk or tofu [2].

In 2010, the annual output of soybean exceeded 261 million tons. As far as Japan is concerned, imported soybean amounted to 3.5 million tons in 2009 according to FAO report [3]. About 800,000 tons of SCR is disposed of annually as byproducts of tofu production in Japan. The expense for SCR disposal costs around 16 billion yen per annum [4]. Currently, SCR is used as stock feed and fertilizer or dumped in landfill. Particularly in Japan, most of the SCR is burnt which will create carbon dioxide [5]. Meanwhile, discarding of SCR as waste is a potential environmental problem because it is highly susceptible to putrefaction [6, 7]. The environmental problems arising from the massive generation of residues have been attracting considerable attention [8]. In fact, SCR also has high moisture content $(70 \%-80 \%)$, which makes it difficult to handle and expensive to dry by conventional means [9]. On the other hand, SCR is a relatively inexpensive source of protein that is widely recognized for its high nutritional and excellent functional properties [10].

This paper reviews the composition and utilization of soybean curd residue. While analysis focuses on the present use of SCR, it also reveals restrictions in the development of SCR, and corresponding solutions are suggested. In addition, the development trends and prospects of SCR are described.

\section{Soybean Curd Residue Composition and Healthy Functions}

2.1. Soybean Curd Residue Composition. The main components of SCR are ruptured cotyledon cells and the soybean seed coat, which is rich in cell wall polysaccharides. Characterization of this byproduct, including the protein, oil, dietary fibre, and mineral composition, along with unspecified monosaccharides and oligosaccharides, can be found in the literature [11-13]. The lyophilized SCR gives $6.99 \% \mathrm{H}$, $46.34 \% \mathrm{C}, 3.99 \% \mathrm{~N}, 0.25 \% \mathrm{~S}$, and $3.59 \%$ metal oxides as ash. 
TABLE 1: Percentage of protein, fat/oil, crude fiber, carbohydrates, and ash, on a dry matter basis, reportedly found in SCR.

\begin{tabular}{|c|c|c|c|c|c|}
\hline Protein & Crude fat & Crude fiber & Carbohydrates & Ash & Reference \\
\hline $24.0(18.2-32.2)$ & $15.2(6.9-22.2)$ & $4.5(9.1-18.6)$ & - & - & Bourne et al., 1976 [58] \\
\hline $25.4-28$ & $9.3-10.9$ & $52.8-58.1$ & $3.8-5.3$ & - & Van der Riet et al., 1989 [11] \\
\hline $26.8 \pm 0.1$ & $22.3 \pm 1.5$ & - & - & - & Guermani et al., 1992 [59] \\
\hline 26.8 & 12.3 & - & 52.9 & - & Ma et al., 1996 [44] \\
\hline 16.1 & 2.2 & - & 52.6 & 5.3 & Hsieh and yang, $2004[1]$ \\
\hline 29.3 & 0.8 & - & 53.6 & 4.0 & Muroyama et al., 2006 [4] \\
\hline 33.4 & 19.8 & 49 & - & 3.5 & Préstamo et al., 2007 [60] \\
\hline 25.0 & 20.0 & 33.0 & - & - & Suruga et al., 2007 [61] \\
\hline 28.5 & 9.8 & 55.5 & 2.6 & 3.6 & Redondo-Cuenca et al., 2008 [9] \\
\hline $33.4 \pm 0.3$ & $8.5 \pm 0.3$ & $54.3 \pm 2.3$ & - & $3.7 \pm 0.2$ & Mateos-Aparicio et al., 2010c [49] \\
\hline 25.5 & 12.0 & 12.2 & 32.6 & 4.0 & Rashad et al., 2011 [62] \\
\hline
\end{tabular}

TABLE 2: Percentage of moisture, protein, fat/oil, crude fiber, carbohydrates, and ash, on a wet matter basis, reportedly found in SCR.

\begin{tabular}{lcccccc}
\hline Moisture & Protein & Crude fat & Crude fiber & Carbohydrate & Ash & Reference \\
\hline 81.0 & 4.8 & 3.6 & 3.3 & 6.4 & 0.8 & Ohno et al., 1996 [48] \\
84.5 & 4.7 & 1.5 & 1.5 & 7.0 & 0.4 & O’Toole, 1999 [12] \\
83.9 & 4.5 & 2.6 & - & 8.3 & 0.7 & Turhan et al., 2007 [63] \\
85.0 & 3.6 & 1.4 & 9.2 & - & - & Zhu et al., 2008 [47] \\
84.5 & 4.2 & 1.5 & 3.52 & 5.78 & 0.55 & Fafaungwithayakul et al., 2011 [64] \\
\hline
\end{tabular}

The composition of SCR is different based on country and processing. The composition of SCR is shown in Tables 1 and 2 .

2.2. Carbohydrates. Soybean curd residue is rich in cellulose, and it accounts for approximately $50 \%$ of the dry weight in soybean with very few calories. It is a good dietary fiber, which cannot be digested in the small intestine but can be fermented by microbes in the large intestine. It is reported that dietary fiber in SCR can reduce blood fat and blood pressure, lower the level of cholesterol in the blood, protect against coronary heart disease, and prevent the occurrence of constipation and colon cancer. It also regulates diabetics' blood sugar levels. Due to these effects, dietary fiber is called the seventh nutrient by nutritionists. Especially, dietary fiber is known to provide important health benefits to the body, with regard to the maintenance of normal bowel function [14]. Studies have shown that combining SCR with soft wheat flour resulted in increased protein, dietary fiber, and isoflavone contents compared with the use of soft wheat flour alone [15]. Several positive effects also have been attributed to the lipid profile in blood plasma, in liver, and in faecal lipid excretion in Syrian golden hamsters fed with SCR [16].

The low-molecular-weight carbohydrates in SCR are shown in Table 3 . The monosaccharide units in the polysaccharides in the insoluble fiber component include glucose, arabinose, and galactose when it is enzymatically digested. SCR also contains rhamnose, mannose, xylose, and uronic acids according to the study of Redondo-Cuenca et al. [9].

In addition, there is some soluble dietary fiber in soybean residue. According to reports in the literature, the amount of soluble dietary fiber in SCR treated by high hydrostatic pressure increased more than 8-fold [17]. Furthermore, soluble dietary fiber plays an important role in the reduction of cholesterol levels in some hyperlipidemic individuals [1820], and it can also be used to improve glucose tolerance in diabetics [21-23]. The soluble fiber in SCR treated by high hydrostatic pressure has anti-inflammatory and anticarcinogenic effects on the digestive tract [24]. On the other hand, insoluble dietary fiber increases faecal bulk and reduces gastrointestinal transit time. Moreover, it seems to have a positive effect on diarrhoea and constipation and as a treatment for irritable bowel [25].

2.3. Protein and Amino Acid. Soybean curd residue has high quality protein, especially essential amino acids. It is well-documented that SCR contains about $27 \%$ protein (dry basis) with good nutritional quality and a superior protein efficiency ratio, which shows a potential source of low cost vegetable protein for human consumption [26, 27]. Table 4 shows the amino acid composition in SCR. The protein in SCR is of better quality than from other soy products; for example, the protein efficiency ratio of SCR is 2.71 compared with 2.11 for soymilk, but the ratio of essential amino acids to total amino acids is similar to tofu and soymilk. It is clear that fermented thua nao, a Thai fermented soybean, has much higher concentrations of amino acids than its unfermented counterparts, which increases the flavor [28]. However the low solubility in water of protein in SCR is detrimental which affects its extraction. Accordingly, many papers focus on how to increase protein extraction from SCR. The related literature illustrates that solubility of protein in SCR treated by acid increased markedly with other functional properties such as emulsifying and foaming properties being 
TABLE 3: Low-molecular-weight carbohydrates from SCR (g/100 g dry matter).

\begin{tabular}{lccccccccc}
\hline Ing. & Rha & Fuc & Ara & Xyl & Man & Gal & Glu & Suc & Reference \\
\hline \multirow{2}{*}{ Content } & 0.85 & 0.45 & 6.35 & 5.13 & 1.26 & 10.83 & 15.01 & - & Redondo-Cuenca et al., 2008 [9] \\
& $0.3 \pm 0.1$ & $0.5 \pm 0.1$ & $5.7 \pm 0.1$ & $2.7 \pm 0.1$ & $1.5 \pm 0.3$ & $10.4 \pm 0.2$ & $11.9 \pm 0.4$ & - & Mateos-Aparicio et al., 2010a [24] \\
& $1.0 \pm 0.1$ & $0.1 \pm 0.0$ & - & - & - & $0.2 \pm 0.0$ & $0.2 \pm 0.0$ & $0.6 \pm 0.1$ & Mateos-Aparicio et al., 2010c [49] \\
\hline
\end{tabular}

Ing.: ingredient, Rha: rhamnose; Fuc: fucose; Ara: arabinose; Xyl: xylose; Man: mannose; Gal: galactose; Glc: glucose; Suc: sucrose.

TABLE 4: Amino acid composition (mg/g protein) in SCR [29].

\begin{tabular}{lc}
\hline Amino acid & Content \\
\hline Aspartic acid & 117 \\
Threonine & 41 \\
Serine & 50 \\
Glutamic acid & 195 \\
Glycine & 46 \\
Alanine & 46 \\
Cysteine + methionine & 26 \\
Valine & 51 \\
Isoleucine & 51 \\
Leucine & 81 \\
Tyrosine + phenylalanine & 95 \\
Lysine & 65 \\
Histidine & 28 \\
Arginine & 75 \\
Proline & 36 \\
Tryptophan & - \\
\hline
\end{tabular}

improved [29]. About 53\% of protein can be recovered from SCR if extracted at $\mathrm{pH} 9.0$ and $80^{\circ} \mathrm{C}$ for $30 \mathrm{~min}$. Protein isolated from SCR had a lower solubility than commercial soy protein isolate considering both acidic and alkaline $\mathrm{pH}$ levels, probably due to protein aggregation. A related essay suggests that the protein recovery is relevant to the particle size, and the maximum protein recovery of $93.4 \%$ was achieved with SCR flour from its fine fractions $(<75 \mu \mathrm{m})$ using a three-step-sequential extraction process [30]. The functional properties of protein from SCR, including emulsification, water and fat binding, and foaming properties, were found to be comparable to the commercial soy isolate. Moreover, the protein in SCR after fermentation produces free amino acid and soy peptide [31]. Therefore the development of protein resources from soybean residue has great potential.

2.4. Soybean Isoflavones. Previous studies have reported that soybean is rich in isoflavones and phenolic compounds. As part of flavone compounds, soybean isoflavones have important biochemical activities. It is a plant chemical that is structurally similar to estrogen. The primary isoflavones present in the whole soybean include glycosides such as genistein, daidzein, syringic, chlorogenic, gallic, and ferulic acids which form the major phenolic compounds and have been credited with performing several health promoting functions [32]. Research suggests soybean isoflavone affects resistance to cancer, prevents osteoporosis, diminishes antibacterial inflammation, and controls cardiovascular disease [33]. Because the soybean isoflavones exist mainly in plumular axis of soybean, during the process of making tofu, most of the soybean isoflavones are left in SCR. Information from the literature confirms that the percentages of total isoflavones lost in water used to soak raw soybeans, SCR, and whey were $4 \%, 31 \%$, and $18 \%$, respectively [34]. A recent paper indicates that the total isoflavone content in acid-hydrolysed SCR powders was much higher than unhydrolysed ones [35]. Table 5 shows the content of twelve isoflavones in SCR on a dry weight basis.

When supercritical carbon dioxide extraction was applied to recover isoflavones from SCR, the amounts of two primary soy isoflavones, genistein and daidzein, in the extracts also increased with a corresponding increase in the amount of ethanol (Armando et al., 2006). The soybean isoflavones were separated by column chromatography and thin layer chromatography in SCR, and their structures were elucidated by spectroscopic means and thin layer chromatography method [36]. The SCR fermented by Monilia sitophila Mont. produces isoflavone ligands which have more biochemical activities than isoflavone glycosides. Producing isoflavone using SCR fermented by microorganisms is extensive and related mainly to food and medicine.

2.5. Other Functional Components in SCR. Soyasaponins constitute a group of nonvolatile, amphiphilic molecules found in a wide variety of legume seeds, such as soybeans, peas, lentils, and lupins [37]. Soybean and soy-based food products are major dietary sources of soyasaponins [38]. Soyasaponins mainly exist in the soybean cotyledons cells, and it will be left in the SCR after soybean products processing. They were reported to have immunostimulatory, antiviral, hepatoprotective, and antitumorigenic properties $[37,39,40]$.

Other components in SCR include minerals, lignans, phytosterols, coumestans, and phytates. The microelements in SCR are shown in Table 6 . These compounds have various physiological and therapeutic functions such as antioxidant capacity, prevention of cardiovascular diseases, and effective chemopreventive agents for certain types of cancer [41]. In addition, bean curd production utilizes most of the soluble nutritional factors, while vitamin B and the fat-soluble nutritional factors are left in SCR which include soyabean lecithin, linoleic acid, linolenic acid, phytosterol, tocopheryl, and vitamin D.

\section{Utilization of Soybean Curd Residue}

Soybean curd residue is a good material which has reuse value and biotransformation possibilities, and it has been described 
TABLE 5: The content of twelve isoflavones in SCR (mg/g dry weight basis) [34].

\begin{tabular}{lccccccccccc}
\hline \multicolumn{3}{c}{ Aglycones (mg) } & \multicolumn{3}{c}{ Glucosides (mg) } & \multicolumn{3}{c}{ Malonyl aglycones (mg) } & \multicolumn{3}{c}{ Acetyl glucosides (mg) } \\
Dai. & Gen. & Gly. & Dai. & Gen. & Gly. & Dai. & Gen. & Gly. & Dai. & Gen. & Gly. \\
\hline 22 & 31 & 1.1 & 48 & 53 & 2.2 & 64 & 130 & 2.8 & - & 3.2 & - \\
\hline
\end{tabular}

Dai.: daidzein; Gen.: genistein; Gly.: glycitein.

TABLE 6: Microelements (mg/100 g dry matter) in SCR [49].

\begin{tabular}{lc}
\hline Ingredient & Content \\
\hline Potassium & $1.35 \pm 0.1$ \\
Sodium & $0.03 \pm 0.0$ \\
Calcium & $0.32 \pm 0.0$ \\
Magnesium & $0.13 \pm 0.0$ \\
Iron & $0.62 \pm 0.1$ \\
Copper & $0.10 \pm 0.0$ \\
Manganese & $0.21 \pm 0.1$ \\
Zinc & $0.29 \pm 0.1$ \\
\hline
\end{tabular}

as a potential source of functional food [24]. In the past, SCR had limited uses because of drying cost, storage, and shipment. Recently, the utilization of by-products from the food industry has become widespread [42]. As a nutritious food byproduct, SCR is no exception. Countries, such as Japan and America, pay more attention to reusing SCR. Previous papers focused on the following aspects. Firstly, the ingredients are directly extracted from wet or dry SCR. Some useful materials such as pectic polysaccharides [43], protein [44], and dietary fiber [9] have been produced using SCR. Secondly, the useful components are extracted from SCR after processing or fermentation by microorganisms. Polysaccharides [45], $\beta$ fructofuranosidase [46], iturin A, ethanol, and methane [5] are produced by SCR under different fermentation conditions. It is reported that some constituents extracted have anticancer functions and antioxidants [47]. Within the food and drug processing industry, some processes use SCR to make biscuits, biodegradable edible paper, fiber beverages, lactic acid [4], and iturin A [48].

3.1. Unfermented Products. The SCR is rich in nutrients. Accordingly, the unfermented products are the most extractive of the products which are made directly from SCR. Great efforts have been undertaken to study the fiber, polysaccharides, and protein in SCR. At the same time, it is considered to be attractive due to its low cost and availability in large quantities as a raw material. Recent research on cell wall polysaccharides concludes that the swelling and water retention capacity of SCR indicates its potential application as a texturing additive [49]. Other authors, research on recovering the oil components of SCR is thought to have potential applications in the cosmetic, pharmaceutical, and food industry [41]. The use of it in food and feed is a natural way of promoting reasonable usage. A little SCR can be added into food as roughage resulting in many advantages: (1) low calorie, (2) providing a full belly as food, and
(3) carbohydrates, which are digested and enter the bloodstream more slowly to balance nutrition.

In the area of SCR extraction, firstly, SCR is a good source of dietary fiber to meet consumers' growing needs as mentioned previously. Dietary fibre can also impart some functional properties to foods, for example, increase water holding capacity, oil holding capacity, emulsification or gel formation. The amount of soluble dietary fiber went up from $38.1 \%$ to $64.8 \%$ after high hydrostatic pressure [24]. Research on Syrian hamsters fed by SCR tested its functional effects and results suggest that the main components of SCR, dietary fibre and protein, could be related to the decrease in the total lipids and cholesterol as well as faecal output increase in highfat fed hamsters [16]. Soybean polysaccharide is another main extractive from SCR, which can be used for water retention and as a food dispersing agent. Moreover, antioxidants are also important products of SCR. Processed SCR products, extrusion food, convenience food, bakery products, and pet food were all chosen for implementation. The use of SCR has received wide attention to date, and various large-scale procedures have been developed. In industrialized production, SCR has been used to produce wrapping paper for food, plastics, cookies, cakes, and pies.

3.2. Fermented Products. As we know, SCR is a loose material consisting of a good source of nutrients. Consequently, it is most suited for microorganism fermentation materials mechanism and processing requirements. For this reason, a number of authors carried out research on the fermentation products using SCR. Some of SCR fermented by various microorganisms for production are shown in Table 7. During fermentation, a series of biochemical reactions occur such as the decomposition of insoluble polymer material into soluble low-molecular-weight compounds and the negative factors of nutrition into favorable factors. The role of cell autolysis creates new nutrients, and biological activity enhances the nutritional value of food. Although the SCR has a high nutritional value its texture is rough because of the high cellulose content and large fiber particles. Also it contains antitrypsin, saponin, and antinutritional factors such as hemagglutinin, which cannot be easily digested. The fermentation process is not only conducive to digestion and absorption of nutrients, but also further improves the nutritional value of SCR. It can eliminate the bean's sense of smell, increase the amount of edible fiber, free amino acids, sugars, fatty acids, vitamin $B_{12}$, vitamin $B_{2}$, and lactoflavin lactochrome through fermentation. Another purpose of SCR is the fertilizer use because organic waste is a good material for fertilization [50]. SCR can be diverted for disposal onto fields as it contains some nutritional properties good for crops and soils, including organic matter. Fungi plays an important 
TABLE 7: SCR fermented by various microorganisms for production.

\begin{tabular}{|c|c|c|c|}
\hline No. & Strain & Products & Authors \\
\hline 1 & Aspergillus japonicus MU-2 & $\beta$-Fructofuranosidase & Hayashi et al., 1992 [46] \\
\hline 2 & NRRL 330 + NCIM 653 & Citric acid & Khare et al., 1995 [2] \\
\hline 3 & Bacillus natto & Crude antioxidant preparation & Hattori et al., 1995 [65] \\
\hline 4 & Bacillus subtilis NB22 & Iturin $\mathrm{A}$ & Ohno et al., 1996 [48] \\
\hline 5 & Methanogens I and II & Methane & Muroyama et al., 2001 [5] \\
\hline 6 & Lactobacillus paracasei & Hydrogen & Noike et al., 2002 [66] \\
\hline 7 & Ganoderma lucidum & Fruiting bodies & Hsieh and yang, 2004 [1] \\
\hline 8 & Lactobacillus paracasei & Lactic acid & Muroyama et al., 2006 [4] \\
\hline 9 & Bacillus subtilis $\mathrm{B} 2$ & Antioxidant & Zhu et al., 2008 [47] \\
\hline 10 & Digestion sludge & Methane & Zhou et al., 2011 [67] \\
\hline 11 & B. subtilis & Phenolic compounds & Chung et al., 2011 [55] \\
\hline 12 & Flammulina velutipes & Polysaccharides & Shi et al., 2012 [45] \\
\hline
\end{tabular}

role in the process of decay, which returns the ingredients of SCR to the soil and enhances soil fertility. As a kind of agricultural waste, SCR is being used as a raw material for energy generation by fermentation, especially methane and ethanol. In actual production, SCR was fermented to produce soy sauce, jam, microbial protein feed, fermented food additive, and beverages.

\section{Restrictive Factors for the Development of Soybean Curd Residue}

The production of SCR throughout the world is large but its utilization ratio is low, which results in poor returns from rich resources. More worryingly, the mistakes in handling are causing a lot of environmental pollution. Many factors limiting the efficient use of SCR are summarized as follows.

4.1. Moisture. The moisture content of SCR is between $70 \%$ and $80 \%$, and it is too high to preserve well; however, the nutrition components are rich. Consequently, SCR will decompose rapidly once they are produced. To overcome these limitations fresh SCR must be dried as early as possible under appropriate drying conditions [51]. The natural drying process is not fit for drying SCR because of the long period required and weather influences. SCR will rot before it is dried by natural drying. The general methods to preserve SCR include freezing of SCR, where low temperatures (from $0^{\circ} \mathrm{C}$ to $-18^{\circ} \mathrm{C}$ or lower) inhibit growth of microorganisms; oven drying, where removal of water from SCR which make it suitable for preservation, and vacuum freeze drying which is another method to handle SCR. However all the common drying methods are energy intensive. Nevertheless, important alterations in flavor, color, and aroma take place. Some studies advocate advancing drying technology of SCR to improve drying quality.

4.2. Antinutrients. Raw soybeans have high antinutritional factors, especially soybean trypsin inhibitors which are partially inactivated during the solvent extraction and toasting process [52]. Trypsin inhibitor is one of the most important factors that limit the application of SCR in animal feed. That is the reason why SCR cannot be fed directly to livestock. Livestock served with SCR will have digestion problem because of the antitrypsin, a further negative effect on its use to facilitate animal growth. The experimental results show that fresh SCR, used as direct feed, has an impact on growth, behavior, and physiological activity [53]. The inactivation methods for soybean trypsin inhibitors include processes utilizing physics, chemistry, bioreduction, and fermentation as well as the complex methods using natural compounds [54].

4.3. Diversify Production. In Asia, SCR is mass produced every day but most tofu and soy milk plants are small-scale workshops, actually a hand-craft workshop. While dispersed SCR is difficult to collect, so is arranging the storage, handling, transportation, and application of this product. Small businesses cannot afford expensive disposal equipment for SCR. One method to solve this problem is the implementation of shared resources. Producers can share arrangements for drying and/or transportation. Regardless, trust and sharing of mutual goals will be important for any company considering the long-term use of SCR. Another way of overcoming this problem is to facilitate tofu and soy milk and form the centralized production. At the same time, the plant which facilitates extensive processing of SCR products near the production area saves transportation costs and decreases the SCR deterioration rate as well.

\section{Prospects for the Utilization of Soybean Curd Residue}

At present, the rational development and utilization of SCR has aroused public concern. A considerable number of studies reported the exploration and development of SCR in the literature. Reasons such as a lack of guidance, a lack of funding, and the fact that some countries are at an obvious disadvantage to the processes established in developed countries are examples. The drawbacks are primarily acts of utilization as this rate is low as well as the utilization 
methods being primitive or simple. In addition, the storage and transportation process of SCR has not reached normal technical standards.

5.1. Food Additive. Finding convenient ways to incorporate SCR into food could eliminate a possible source of pollution and add economic value to this currently valueless product. The use of SCR, as a food additive, is one of the developing trends, which has an important economic function and social meaning. Adding SCR to bakery products, without further processing or as an ingredient in consumer ready products, can reduce production cost upgrade quality. Recently, food packaging must not just look good and be practical but the environmental protection design has become an important consideration for the packaging industry. As the food packaging and medical packaging market will continue to show strong growth momentum, green food packaging designs using SCR will become one of the most important developments in this field.

5.2. Microbiological Medium. Animalcule fermentation with SCR is the beginning of a new way forward. As a cheap culture with good characteristics using different fungi, the product has functional components and has been trialled including the production of sauce, juice, and edible fungi [55]. To develop function foods by utilizing the resources of SCR is an important way for SCR industries to go into the future markets. Some of the benefits of producing ethanol from agricultural residues are the reduction of the potential contamination of air, water, and soil associated with the land application of organic residuals [56]. Biogas systems provide the basis of material recycling and energy transformation of a complex agroecosystem. As a food product residue, SCR is an even more promising source of biogas. The biogas residue of SCR can be widely used in agriculture and stockbreeding for its rich nutrient content and microelements as well as to improve the immunity of crop and livestock.

5.3. Other Products. It is more and more important to expand the industrial chain of SCR. Increasing the value added step by step and reducing the harm to the environment are becoming the key points. Therefore, other high-valueadded products are made using SCR, including protein, polysaccharide, isoflavones, and antioxidant substance [47]. SCR is also used in other ways, producing $\beta$-SiC and $a-\mathrm{Si}_{3} \mathrm{Ni}_{4}$ whiskers [57], ethanol, and methane [5]. The Japanese have patented a process in which SCR is used to make a reinforced ceramic via the Pozzolanic reaction. The carbonized SCR reacts with $\mathrm{SiO}_{2}$ to form silicon carbide that strengthens the ceramic product. Also, a kind of pet product which is used to collect the cat waste at home has started selling in Japan.

\section{Conclusions}

This paper has reviewed SCR composition and health functions, utilization, restrictive factors, and current directions in the development direction of waste materials that are thrown away but require comprehensive utilization. Although the amount of the available literature on the use of SCR products is increasing at a tremendous pace, there are still several gaps which need to be filled. SCR products with extensive development prospects need further research and summarization.

\section{References}

[1] C. Hsieh and F. C. Yang, "Reusing soy residue for the solid-state fermentation of Ganoderma lucidum," Bioresource Technology, vol. 91, no. 1, pp. 105-109, 2004.

[2] S. K. Khare, K. Jha, and A. P. Gandhi, "Citric acid production from okara (soy-residue) by solid-state fermentation," Bioresource Technology, vol. 54, no. 3, pp. 323-325, 1995.

[3] FAO, "Food and Agriculture organization of the United States," 2009, http://faostat.fao.org/site/339/default.aspx.

[4] K. Muroyama, R. Atsumi, and A. Andoh, "Effect of pretreatment on lactic acid fermentation of bean curd refuse with simultaneous saccharification," Studies in Surface Science and Catalysis, vol. 159, pp. 133-136, 2006.

[5] K. Muroyama, T. Mochizuki, and T. Wakamura, "Methane fermentation of bean curd refuse," Journal of Bioscience and Bioengineering, vol. 91, no. 2, pp. 208-212, 2001.

[6] J. J. Almaraz, X. M. Zhou, F. Mabood et al., "Greenhouse gas fluxes associated with soybean production under two tillage systems in Southwestern Quebec," Soil and Tillage Research, vol. 104, no. 1, pp. 134-139, 2009.

[7] C. Song, Y. Kitamura, S. Li, and K. Ogasawara, "Design of a cryogenic $\mathrm{CO}_{2}$ capture system based on Stirling coolers," International Journal of Greenhouse Gas Control, vol. 7, pp. 107114, 2012.

[8] F. Cuadros, F. López-Rodríguez, A. Ruiz-Celma, F. Rubiales, and A. González-González, "Recycling, reuse and energetic valuation of meat industry wastes in extremadura (Spain)," Resources, Conservation and Recycling, vol. 55, no. 4, pp. 393399, 2011.

[9] A. Redondo-Cuenca, M. J. Villanueva-Suárez, and I. MateosAparicio, "Soybean seeds and its by-product okara as sources of dietary fibre. Measurement by AOAC and Englyst methods," Food Chemistry, vol. 108, no. 3, pp. 1099-1105, 2008.

[10] Y. Cheng, N. Shimizu, and T. Klmura, "The viscoelastic properties of soybean curd (tofu) as affected by soymilk concentration and type of coagulant," International Journal of Food Science and Technology, vol. 40, no. 4, pp. 385-390, 2005.

[11] W. B. van der Riet, A. W. Wight, J. J. L. Cilliers, and J. M. Datel, "Food chemical investigation of tofu and its byproduct okara," Food Chemistry, vol. 34, no. 3, pp. 193-202, 1989.

[12] D. K. O'Toole, "Characteristics and use of okara, the soybean residue from soy milk production-a review," Journal of Agricultural and Food Chemistry, vol. 47, no. 2, pp. 363-371, 1999.

[13] O. Surel and B. Couplet, "Influence of the dehydration process on active compounds of okara during its fractionation," Journal of the Science of Food and Agriculture, vol. 85, no. 8, pp. 13431349, 2005.

[14] M. J. Periago, G. Ros, F. Rincón, and C. Martínez, "Nutritional meaning of dietary fibre and phytic acid in meat-based homogenised weaning foods," Food Research International, vol. 30, no. 3-4, pp. 223-230, 1997.

[15] V. E. A. Rinaldi, P. K. W. Ng, and M. R. Bennink, "Effects of extrusion on dietary fiber and isoflavone contents of wheat 
extrudates enriched with wet okara," Cereal Chemistry, vol. 77, no. 2, pp. 237-240, 2000.

[16] M. J. Villanueva, W. H. Yokoyama, Y. J. Hong, G. E. Barttley, and P. Rupérez, "Effect of high-fat diets supplemented with okara soybean by-product on lipid profiles of plasma, liver and faeces in Syrian hamsters," Food Chemistry, vol. 124, no. 1, pp. 72-79, 2011.

[17] I. Mateos-Aparicio, C. Mateos-Peinado, and P. Rupérez, "High hydrostatic pressure improves the functionality of dietary fibre in okara by-product from soybean," Innovative Food Science and Emerging Technologies, vol. 11, no. 3, pp. 445-450, 2010.

[18] J. W. Anderson, B. M. Smith, and C. S. Washnock, "Cardiovascular and renal benefits of dry bean and soybean intake," The American Journal of Clinical Nutrition, vol. 70, no. 3, pp. 464474, 1999.

[19] L. H. Kushi, K. A. Meyer, and D. R. Jacobs Jr., "Cereals, legumes, and chronic disease risk reduction: evidence from epidemiologic studies," The American Journal of Clinical Nutrition, vol. 70, no. 3, pp. 451-458, 1999.

[20] K. Reynolds, A. Chin, K. A. Lees, A. Nguyen, D. Bujnowski, and J. He, "A meta-analysis of the effect of soy protein supplementation on serum lipids," The American Journal of Cardiology, vol. 98, no. 5, pp. 633-640, 2006.

[21] M. J. Messina, "Legumes and soybeans: overview of their nutritional profiles and health effects," The American Journal of Clinical Nutrition, vol. 70, no. 3, pp. 439-450, 1999.

[22] M. Chandalia, A. Garg, D. Lutjohann, K. von Bergmann, S. M. Grundy, and L. J. Brinkley, "Beneficial effects of high dietary fiber intake in patients with type 2 diabetes mellitus," The New England Journal of Medicine, vol. 342, no. 19, pp. 1392-1398, 2000.

[23] D. J. A. Jenkins, C. W. C. Kendall, L. S. A. Augustin et al., "Glycemic index: overview of implications in health and disease," The American Journal of Clinical Nutrition, vol. 76, no. 1, pp. 266-273, 2002.

[24] I. Mateos-Aparicio, C. Mateos-Peinado, A. Jiménez-Escrig, and P. Rupérez, "Multifunctional antioxidant activity of polysaccharide fractions from the soybean byproduct okara," Carbohydrate Polymers, vol. 82, no. 2, pp. 245-250, 2010.

[25] I. Bosaeus, "Fibre effects on intestinal functions (diarrhoea, constipation and irritable bowel syndrome)," Clinical Nutrition, Supplement, vol. 1, no. 2, pp. 33-38, 2004.

[26] H. L. Wang and J. F. Cavins, "Yield and amino acid composition of fractions obtained during tofu production," Cereal Chemistry, vol. 66, pp. 359-361, 1989.

[27] J. A. Zee, A. Boudreau, M. Bourgeois, and R. Breton, "Chemical composition and nutritional quality of faba bean (Vicia faba L. Minor) based tofu," Journal of Food Science, vol. 53, no. 6, pp. 1772-1774, 1988.

[28] K. Dajanta, A. Apichartsrangkoon, E. Chukeatirote, and R. A. Frazier, "Free-amino acid profiles of thua nao, a Thai fermented soybean," Food Chemistry, vol. 125, no. 2, pp. 342-347, 2011.

[29] W. M. Chan and C. Y. Ma, "Acid modification of proteins from soymilk residue (okara)," Food Research International, vol. 32, no. 2, pp. 119-127, 1999.

[30] K. H. Vishwanathan, V. Singh, and R. Subramanian, "Influence of particle size on protein extractability from soybean and okara," Journal of Food Engineering, vol. 102, no. 3, pp. 240-246, 2011.

[31] H. J. Chae, M. J. In, and M. H. Kim, "Characteristic properties of enzymically hydrolyzed soy protein for the use in protein supplements," Agricultural Chemistry and Biotechnology, vol. 40, no. 5, pp. 404-408, 1997.

[32] J. A. Kim, W. S. Jung, S. C. Chun et al., "A correlation between the level of phenolic compounds and the antioxidant capacity in cooked-with-rice and vegetable soybean (Glycine max L.) varieties," European Food Research and Technology, vol. 224, no. 2, pp. 259-270, 2006.

[33] Y. B. Lee, H. J. Lee, and H. S. Sohn, "Soy isoflavones and cognitive function," Journal of Nutritional Biochemistry, vol. 16, no. 11, pp. 641-649, 2005.

[34] C. J. C. Jackson, J. P. Dini, C. Lavandier et al., "Effects of processing on the content and composition of isoflavones during manufacturing of soy beverage and tofu," Process Biochemistry, vol. 37, no. 10, pp. 1117-1123, 2002.

[35] T. S. Tyug, K. N. Prasad, and A. Ismail, "Antioxidant capacity, phenolics and isoflavones in soybean by-products," Food Chemistry, vol. 123, no. 3, pp. 583-589, 2010.

[36] A. P. Griffith and M. W. Collison, "Improved methods for the extraction and analysis of isoflavones from soycontaining foods and nutritional supplements by reversedphase high-performance liquid chromatography and liquid chromatography-mass spectrometry," Journal of Chromatography A, vol. 913, no. 1-2, pp. 397-413, 2001.

[37] R. Lásztity, M. Hidvégi, and A. Bata, "Saponins in food," Food Reviews International, vol. 14, no. 4, pp. 371-390, 1998.

[38] D. E. Fenwick and D. Oakenfull, "Saponin content of food plants and some prepared foods," Journal of the Science of Food and Agriculture, vol. 34, no. 2, pp. 186-191, 1983.

[39] E. A. Bae, M. J. Han, M. K. Choo, S. Y. Park, and D. H. Kim, "Metabolism of 20(S)- and 20(R)-ginsenoside Rg3 by human intestinal bacteria and its relation to in vitro biological activities," Biological \& Pharmaceutical Bulletin, vol. 25, no. 1, pp. 58-63, 2002.

[40] D. M. Gurfinkel and A. V. Rao, "Soyasaponins: the relationship between chemical structure and colon anticarcinogenic activity," Nutrition and Cancer, vol. 47, no. 1, pp. 24-33, 2003.

[41] A. T. Quitain, K. Oro, S. Katoh, and T. Moriyoshi, "Recovery of oil components of okara by ethanol-modified supercritical carbon dioxide extraction," Bioresource Technology, vol. 97, no. 13, pp. 1509-1514, 2006.

[42] A. Schieber, F. C. Stintzing, and R. Carle, "By-products of plant food processing as a source of functional compounds-recent developments," Trends in Food Science and Technology, vol. 12, no. 11, pp. 401-413, 2001.

[43] F. Yamaguchi, Y. Ota, and C. Hatanaka, "Extraction and purification of pectic polysaccharides from soybean okara and enzymatic analysis of their structures," Carbohydrate Polymers, vol. 30, no. 4, pp. 265-273, 1996.

[44] C. Y. Ma, W. S. Liu, K. C. Kwok, and F. Kwok, "Isolation and characterization of proteins from soymilk residue (okara)," Food Research International, vol. 29, no. 8, pp. 799-805, 1996.

[45] M. Shi, Y. Yang, D. Guan, Y. Wang, and Z. Zhang, "Bioactivity of the crude polysaccharides from fermented soybean curd residue by Flammulina velutipes," Carbohydrate Polymers, vol. 89, no. 4, pp. 1268-1276, 2012.

[46] S. Hayashi, K. Matsuzaki, T. Kawahara, Y. Takasaki, and K. Imada, "Utilisation of soybean residue for the production of $\beta$ fructofuranosidase," Bioresource Technology, vol. 41, no. 3, pp. 231-233, 1992.

[47] Y. P. Zhu, J. F. Fan, Y. Q. Cheng, and L. T. Li, "Improvement of the antioxidant activity of Chinese traditional fermented okara 
(Meitauza) using Bacillus subtilis B2," Food Control, vol. 19, no. 7, pp. 654-661, 2008.

[48] A. Ohno, T. Ano, and M. Shoda, "Use of soybean curd residue, okara, for the solid state substrate in the production of a lipopeptide antibiotic, iturin A, by Bacillus subtilis NB22," Process Biochemistry, vol. 31, no. 8, pp. 801-806, 1996.

[49] I. Mateos-Aparicio, A. Redondo-Cuenca, and M. J. VillanuevaSuárez, "Isolation and characterisation of cell wall polysaccharides from legume by-products: okara (soymilk residue), pea pod and broad bean pod," Food Chemistry, vol. 122, no. 1, pp. 339-345, 2010.

[50] J. W. C. Wong, K. F. Mak, N. W. Chan et al., "Co-composting of soybean residues and leaves in Hong Kong," Bioresource Technology, vol. 76, no. 2, pp. 99-106, 2001.

[51] S. Wachiraphansakul and S. Devahastin, "Drying kinetics and quality of okara dried in a jet spouted bed of sorbent particles," LWT-Food Science and Technology, vol. 40, no. 2, pp. 207-219, 2007.

[52] B. J. Marty and E. R. Chavez, "Ileal digestibilities and urinary losses of amino acids in pigs fed heat processed soybean products," Livestock Production Science, vol. 43, no. 1, pp. 37-48, 1995.

[53] C. F. Hinks and D. Hupka, "The effects of feeding leaf sap from oats and wheat, with and without soybean trypsin inhibitor, on feeding behaviour and digestive physiology of adult males of Melanoplus sanguinipes," Journal of Insect Physiology, vol. 41, no. 11, pp. 1007-1015, 1995.

[54] T. Ao, A. H. Cantor, A. J. Pescatore, J. L. Pierce, and K. A. Dawson, "Effects of citric acid, alpha-galactosidase and protease inclusion on in vitro nutrient release from soybean meal and trypsin inhibitor content in raw whole soybeans," Animal Feed Science and Technology, vol. 162, no. 1-2, pp. 58-65, 2010.

[55] I. M. Chung, S. H. Seo, J. K. Ahn, and S. H. Kim, "Effect of processing, fermentation, and aging treatment to content and profile of phenolic compounds in soybean seed, soy curd and soy paste," Food Chemistry, vol. 127, no. 3, pp. 960-967, 2011.

[56] P. Champagne, "Feasibility of producing bio-ethanol from waste residues: a Canadian perspective. Feasibility of producing bioethanol from waste residues in Canada," Resources, Conservation and Recycling, vol. 50, no. 3, pp. 211-230, 2007.

[57] S. Motojima, Y. Ogawa, S. Gakei, and H. Iwanaga, "Preparation of $\mathrm{SiC}$ and $\mathrm{Si}_{3} \mathrm{~N}_{4}$ whiskers using bean-curd refuse as the $\mathrm{Si}$ source," Materials Science and Engineering B, vol. 30, no. 1, pp. 13-17, 1995.

[58] M. C. Bourne, M. G. Clemente, and J. Banzon, "Survey of the suitability of thirty cultivars of soybeans for soymilk manufacture," Journal of Food Science, vol. 41, no. 5, pp. 12041208, 1976.

[59] L. Guermani, C. Villaume, H. W. Bau, V. Chandrasiri, J. P. Nicolas, and L. Mejean, "Composition and nutritional value of okara fermented by Rhizopus oligosporus," Science Aliment, vol. 12, no. 3, pp. 441-451, 1992.

[60] G. Préstamo, P. Rupérez, I. Espinosa-Martos, M. J. Villanueva, and M. A. Lasunción, "The effects of okara on rat growth, cecal fermentation, and serum lipids," European Food Research and Technology, vol. 225, no. 5-6, pp. 925-928, 2007.

[61] K. Suruga, A. Kato, K. Kadokura et al., “'Okara' a new preparation of food material with antioxidant activity and dietary fiber from soybean," Soybean and Nutrition, vol. 16, pp. 311-326, 2007.

[62] M. M. Rashad, A. E. Mahmoud, H. M. Abdou, and M. U. Nooman, "Improvement of nutritional quality and antioxidant activities of yeast fermented soybean curd residue," African Journal of Biotechnology, vol. 10, no. 28, pp. 5504-5513, 2011.

[63] S. Turhan, H. Temiz, and I. Sagir, "Utilization of wet okara in low-fat beef patties," Journal of Muscle Foods, vol. 18, no. 2, pp. 226-235, 2007.

[64] N. Fafaungwithayakul, P. Hongsprabhas, and P. Hongsprabhas, "Effect of soy soluble polysaccharide on the stability of soystabilised emulsions during in vitro protein digestion," Food Biophysics, vol. 6, no. 3, pp. 407-415, 2011.

[65] T. Hattori, H. Ohishi, T. Yokota, H. Ohoami, and K. Watanabe, "Antioxidative effect of crude antioxidant preparation from soybean fermented by Bacillus natto," LWT-Food Science and Technology, vol. 28, no. 1, pp. 135-138, 1995.

[66] T. Noike, H. Takabatake, O. Mizuno, and M. Ohba, "Inhibition of hydrogen fermentation of organic wastes by lactic acid bacteria," International Journal of Hydrogen Energy, vol. 27, no. 11-12, pp. 1367-1371, 2002.

[67] Y. Zhou, Z. Zhang, T. Nakamoto et al., "Influence of substrateto-inoculum ratio on the batch anaerobic digestion of bean curd refuse-okara under mesophilic conditions," Biomass and Bioenergy, vol. 35, no. 7, pp. 3251-3256, 2011. 

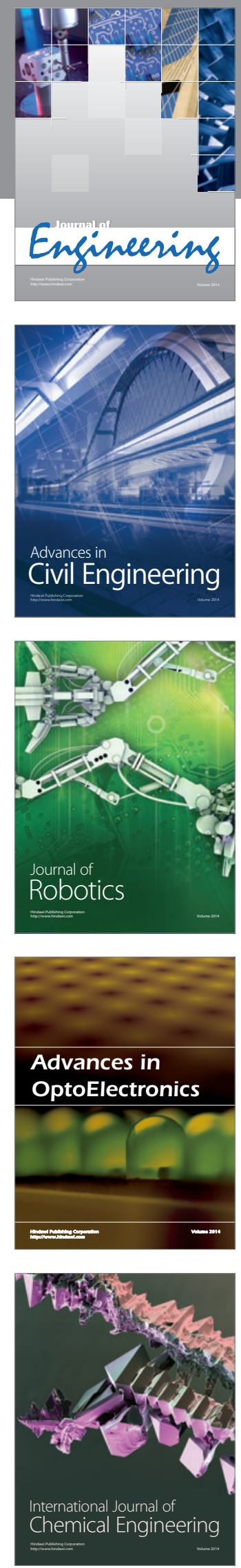

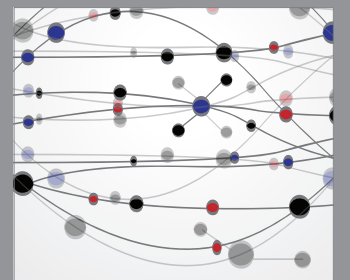

The Scientific World Journal
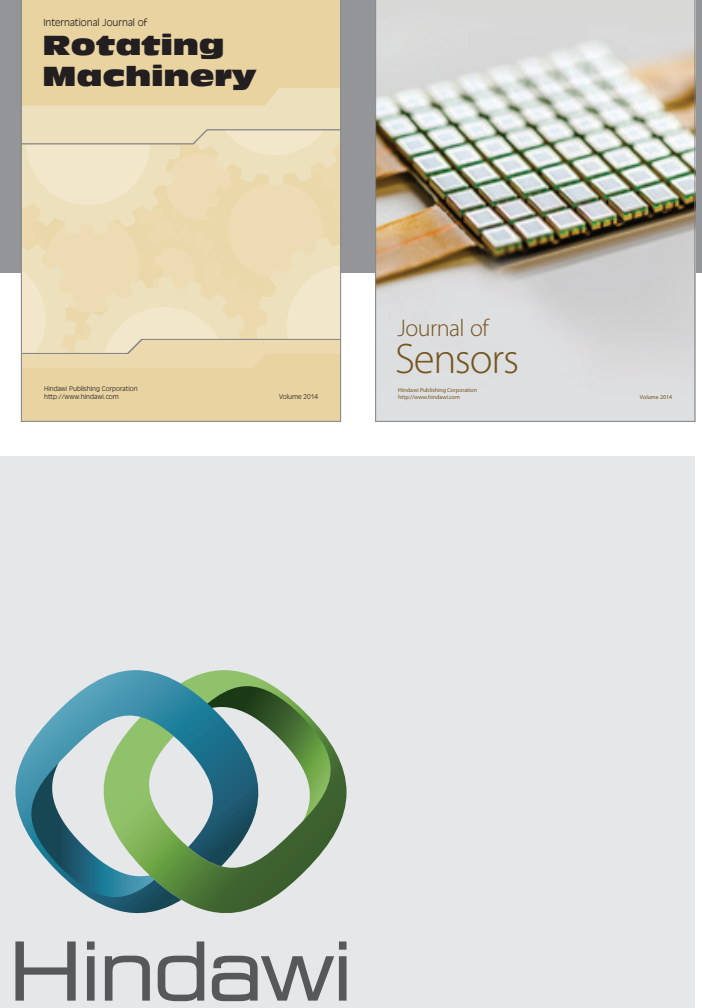

Submit your manuscripts at http://www.hindawi.com
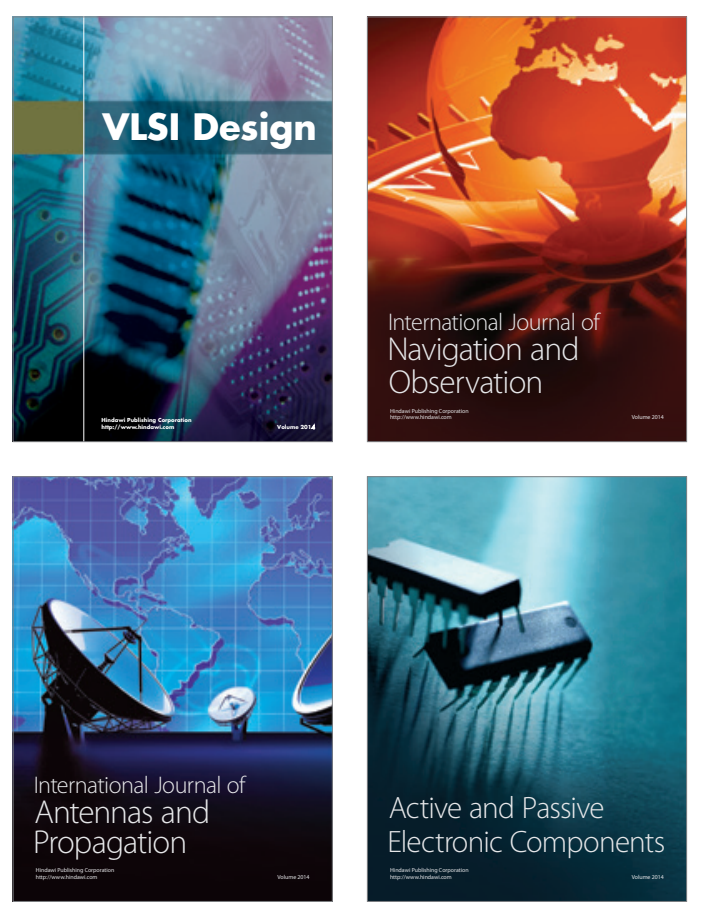
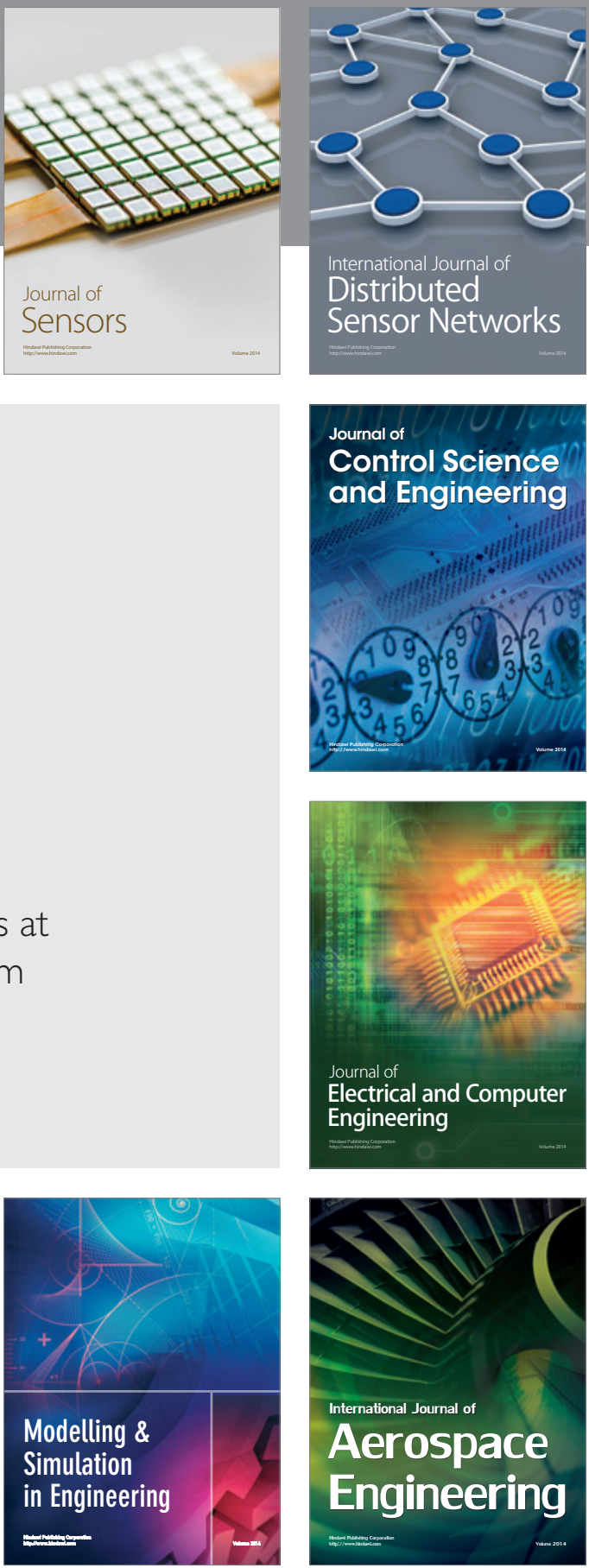

Journal of

Control Science

and Engineering
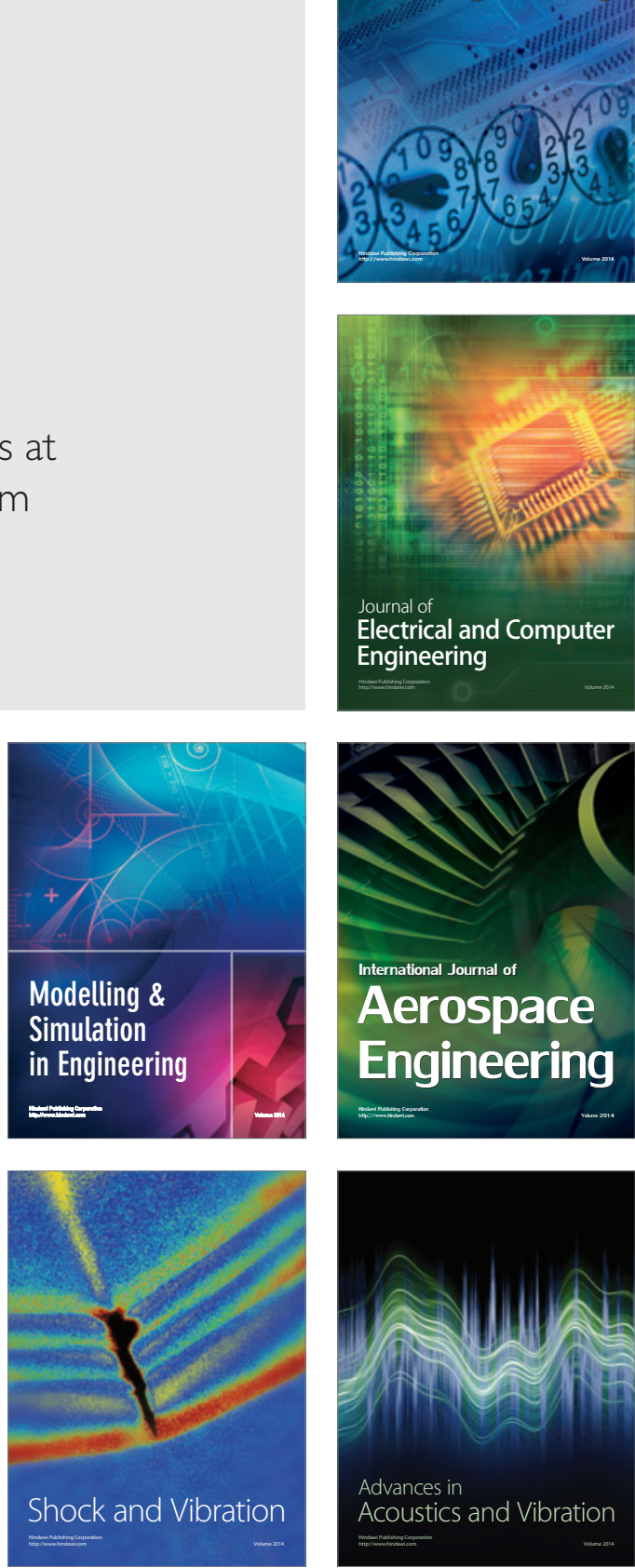